\title{
Kit transduced signals counteract erythroid maturation by MAPK-dependent modulation of erythropoietin signaling and apoptosis induction in mouse fetal liver
}

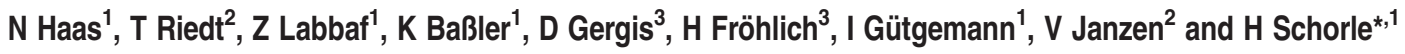

Signaling by the stem cell factor receptor Kit in hematopoietic stem and progenitor cells is functionally associated with the regulation of cellular proliferation, differentiation and survival. Expression of the receptor is downregulated upon terminal differentiation in most lineages, including red blood cell terminal maturation, suggesting that omission of Kit transduced signals is a prerequisite for the differentiation process to occur. However, the molecular mechanisms by which Kit signaling preserves the undifferentiated state of progenitor cells are not yet characterized in detail. In this study, we generated a mouse model for inducible expression of a Kit receptor carrying an activating mutation and studied its effects on fetal liver hematopoiesis. We found that sustained Kit signaling leads to expansion of erythroid precursors and interferes with terminal maturation beyond the erythroblast stage. Primary KIT ${ }^{\mathrm{DB16V}}$ erythroblasts stimulated to differentiate fail to exit cell cycle and show elevated rates of apoptosis because of insufficient induction of survival factors. They further retain expression of progenitor cell associated factors c-Myc, c-Myb and GATA-2 and inefficiently upregulate erythroid transcription factors GATA-1, KIf1 and Tal1. In KIT ${ }^{\text {816V }}$ erythroblasts we found constitutive activation of the mitogen-activated protein kinase (MAPK) pathway, elevated expression of the src kinase family member Lyn and impaired Akt activation in response to erythropoietin. We demonstrate that the block in differentiation is partially rescued by MAPK inhibition, and completely rescued by the multikinase inhibitor Dasatinib. These results show that a crosstalk between Kit and erythropoietin receptor signaling cascades exists and that continuous Kit signaling, partly mediated by the MAPK pathway, interferes with this crosstalk.

Cell Death and Differentiation (2015) 22, 790-800; doi:10.1038/cdd.2014.172; published online 17 October 2014

Erythroid cell proliferation, differentiation and survival are tightly regulated to ensure supply of the organism with sufficient numbers of red blood cells. Regulation of these processes is governed by two major signaling receptors, the stem cell factor (SCF) receptor Kit and the erythropoietin receptor (EpoR). Kit is expressed in hematopoietic stem and progenitor cells and becomes downregulated upon differentiation of colony-forming unit erythroid cells. ${ }^{1}$ EpoR gets upregulated after erythroid commitment and is expressed until later erythroblast stages. ${ }^{2}$ Both receptors are essential for erythroid development, as Kit or EpoR-deficient mice die in utero because of impaired fetal liver erythropoiesis. ${ }^{3,4}$ The roles of Kit and EpoR in erythropoiesis are partially overlapping and signal integration after co-stimulation results in proliferative synergy and enhanced survival..$^{5-7}$ However, Kit has been attributed a primary role in proliferation, ${ }^{8,9}$ whereas EpoR has its main role in mediating differentiation and survival. ${ }^{10}$

In terms of intracellular signaling, stimulation of either Kit or EpoR can activate the phosphoinositide 3-kinase (PI3K) and the mitogen-activated protein kinase (MAPK) pathways. ${ }^{11-13}$
Src family kinases (SFKs) like Lyn ${ }^{14}$ provide an important signaling route downstream of Kit and mediate Ras/MAPK signaling and crosstalk to the EpoR. ${ }^{6,15}$ Transphosphorylation of EpoR upon Kit stimulation has been shown, which is also dependent on SFKs. ${ }^{6}$ Furthermore, Lyn has also a role in signal transduction downstream of EpoR. ${ }^{16}$ EpoR activates the janus family kinase (JAK)/signal transducers and activators of transcription (Stat) pathway by first activating tethered Jak2, which then mediates phosphorylation of EpoR tyrosine residues to provide docking sites for signaling mediators including Stat5. ${ }^{13,17}$

A number of transcriptional regulators have been described as indispensable for erythroid development, including GATA-2, c-Myc and c-Myb, which are associated with proliferation of immature cells. ${ }^{18-20}$ GATA-1 is considered as the master regulator of erythropoiesis regulating commitment, differentiation and survival and Scl/Tal1 has a role in erythroid commitment and differentiation. ${ }^{21-24}$ A key effector for erythroid differentiation is the anti-apoptotic protein $\mathrm{Bcl}-\mathrm{xL}$, which mediates cell survival during terminal maturation. ${ }^{21}$

\footnotetext{
${ }^{1}$ Department of Developmental Pathology, Institute of Pathology, University of Bonn Medical School, Bonn, Germany; ${ }^{2}$ Department of Internal Medicine III, Hematology and Oncology, University of Bonn Medical School, Bonn, Germany and ${ }^{3}$ Bonn-Aachen International Center for IT (B-IT) Algorithmic Bioinformatics, University of Bonn, Bonn, Germany

*Corresponding author: H Schorle, Department of Developmental Pathology, Institute of Pathology, University of Bonn Medical School, Sigmund-Freud-Strasse 25, Bonn 53127, Germany. Tel: +49 228287 16342; Fax: +49 228287 19757; E-mail: Hubert.Schorle@ukb.uni-bonn.de

Abbreviations: SCF, stem cell factor; EpoR, erythropoietin receptor; PI3K, phosphoinositide 3-kinase; MAPK, mitogen-activated protein kinase; SFK, Src family kinase; JAK, janus family kinase; Stat, signal transducers and activators of transcription; GFP, green fluorescent protein; LSL, IoxP-STOP-IOXP; Sox2:KIT D816V, Sox2-Cre:R26-LSL$\mathrm{KIT}^{\mathrm{D} 16 \mathrm{~V}}$ mice; Vav:KIT ${ }^{\mathrm{D} 816 \mathrm{~V}}$, Vav-iCre:R26-LSL-KIT ${ }^{\mathrm{D} 816 \mathrm{~V}}$ mice; ProE, proerythroblast; BasoE, basophilic erythroblast; PolyE, polychromatic erythroblast; OrthoE, orthochromatic erythroblast; Reti, reticulocyte; Dex, dexamethasone; Gusb, glucuronidase; Sdha, succinate dehydrogenase

Received 20.2.14; revised 08.9.14; accepted 16.9.14; Edited by R De Maria; published online 17.10.14
} 
Here, we asked by which means Kit signaling modulates terminal erythroid differentiation and chose a gain-of-function approach to get insight into that process. We generated and analyzed a conditional mouse model for ectopic expression of a Kit receptor carrying the activating D816V substitution. We found that $\mathrm{KIT}^{\mathrm{D} 816 \mathrm{~V}}$ results in expansion of fetal liver erythroblasts and partially blocks terminal erythropoiesis. Primary $\mathrm{KIT}^{\mathrm{D} 816 \mathrm{~V}}$ erythroblasts cultured under differentiation conditions fail to induce GATA-1 and Bcl-xL expression and show elevated rates of apoptosis. KIT ${ }^{\mathrm{D} 816 \mathrm{~V}}$ cells continue proliferation and maintain expression of GATA-2, c-Myc and c-Myb. We investigated the Epo response of $\mathrm{KIT}^{\mathrm{D} 816 \mathrm{~V}}$ cells and found reduced Akt phosphorylation, showing that Kit modulates the cellular response to differentiation stimuli. We demonstrate that MAPK signaling is constitutively active in $\mathrm{KIT}^{\mathrm{D} 816 \mathrm{~V}}$ erythroblasts. Terminal differentiation can be partially restored upon administration of the MEK1/2 inhibitor U0126, indicating that MAPK activity contributes to the phenotype observed. Further, $\mathrm{KIT}^{\mathrm{D} 816 \mathrm{~V}}$ cells display elevated expression and phosphorylation of Lyn. The dual Kit/SFK inhibitor Dasatinib fully restores differentiation of KIT ${ }^{\mathrm{D} 816 \mathrm{~V}}$ erythroblasts, indicating involvement of other signaling pathways beside MAPK.

\section{Results}

Generation of transgenic mice. A mutation in the Kit gene causing an aspartate-to-valin substitution at position 814 in mice or the homologous position 816 in humans renders the receptor constitutively active independent of ligand binding and receptor dimerization. Although cell surface expression of the $\mathrm{KIT}^{\mathrm{D} 816 \mathrm{~V}}$ receptor is reduced and its localization shifted to the Golgi apparatus, it has been demonstrated that $\mathrm{KIT}^{\mathrm{D} 816 \mathrm{~V}}$ activates the major signaling pathways that are also induced by the ligand-dependent wild-type receptor. ${ }^{25}$ Implication of the D816V mutation in the pathogenesis of myeloproliferative disease demonstrates a critical role of $\mathrm{KIT}^{\mathrm{D} 816 \mathrm{~V}}$ transduced signals in the development of myeloid cells. ${ }^{26,27}$ Although extrapolations regarding the physiological mechanisms of Kit signaling during myeloid cell differentiation must be made with caution, it is thus reasonable that similar signaling events are activated by the mutant $\mathrm{KIT}^{\mathrm{D} 816 \mathrm{~V}}$ receptor and valuable insights can be provided by such a model. We therefore generated a conditional mouse line with knock-in of a chimeric KIT receptor carrying the D816V mutation in the ROSA26 locus. The receptor consists of the murine extracellular and transmembrane domains and the human intracellular domain (Supplementary Figure 1A) and shows fully transforming potential in murine cells. ${ }^{25}$ We linked the KIT cDNA to a green fluorescent protein (GFP) coding sequence from copepod Pontellina plumata by a viral $2 \mathrm{~A}$ sequence ${ }^{28}$ to generate the GFP-2A-KIT ${ }^{\mathrm{D} 818 \mathrm{~V}}$ fusion protein, hereafter called $\mathrm{KIT}^{\mathrm{D} 816 \mathrm{~V}}$. During translation the 2A-peptide mediates separation of GFP and KIT, allowing reliable tracking with minimal alteration of the receptor. Figure 1a illustrates introduction of the $\mathrm{KIT}^{\mathrm{D} 816 \mathrm{~V}}$ transgene into the ROSA26 genomic locus, generating the R26-LSL-KIT ${ }^{\mathrm{D} 816 \mathrm{~V}}$ allele. The transcriptional LSL-STOP cassette prevents $\mathrm{KIT}^{\mathrm{D} 816 \mathrm{~V}}$ expression before Cre-induced recombination.



b
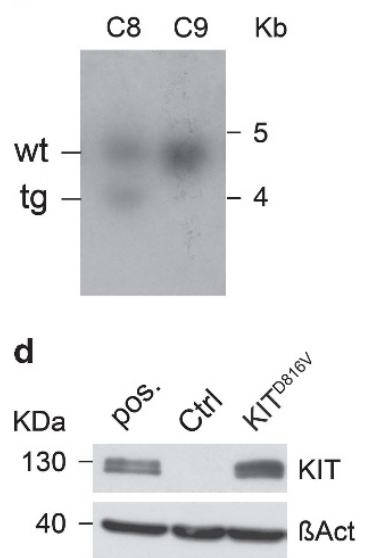

C

Figure 1 Generation of R26-LSL-KIT ${ }^{\mathrm{D} 816 \mathrm{~V}}$ mice. (a) Shows an illustration of the targeting strategy. The GFP-2A-KIT ${ }^{\mathrm{D} 816 \mathrm{~V}}$ cassette codes for the GFP from copepod pontellina plumata and the mutated $\mathrm{KIT}^{\mathrm{D} 816 \mathrm{~V}}$ receptor fused via a $2 \mathrm{~A}$-peptide that mediates co-translational cleavage. To generate the targeting vector (a, upper middle) the GFP-2A-KIT ${ }^{\mathrm{D} 816 \mathrm{~V}}$ was integrated into a plasmid containing ROSA26 homology sequences downstream a loxP-flanked (black triangles) transcriptional STOP cassette (LSL) containing a puromycin selectable marker (PAC-3pA). Integration into intron 1 of the wild-type ROSA26 allele (a, top) yields the R26-LSL-KIT ${ }^{\text {D816V }}$ allele (a, lower middle). The GFP-2A-KIT ${ }^{\mathrm{D} 816 \mathrm{~V}}$ cassette gets expressed only after Cre recombinase-mediated exision of the LSL cassette. LSL: IoxP-STOP-IoxP. pA: polyadenylation sequence. PAC: puromycin $\mathrm{N}$-acetyl-transferase. SA, splice acceptor. (b) Southern blot analysis of two representative embryonic stem cell clones. tg, targeted allele; wt, wild-type allele. (c) R26-LSL-KIT ${ }^{\mathrm{D} 816 \mathrm{~V}}$ mice were mated to Sox2-Cre mice to activate KIT ${ }^{\mathrm{D} 16 \mathrm{~V}}$ expression in the embryo proper. GFP fluorescence indicates successful removal of the LSL cassette and induction of KIT ${ }^{\mathrm{D} 16 \mathrm{~V}}$ expression. Scale bar: $2 \mathrm{~mm}$. (d) Immunoblot analysis for confirmation of $\mathrm{KIT}^{\mathrm{D} 816 \mathrm{~V}}$ expression in E13.5 embryos. Lane one: positive control; lane two: wild-type or single transgenic control embryos (Ctrl), lane three: Sox2:KIT ${ }^{\mathrm{D} 16 \mathrm{~V}}$ embryos. The human intracellular KIT domain is recognized by the antibody with much higher affinity than the murine form, allowing discrimination from endogenous Kit expression

Targeting was confirmed by Southern blot analysis (Figure 1b). Blastocyst injection and subsequent germline transmission yielded R26-LSL-KIT ${ }^{\mathrm{D} 816 \mathrm{~V}}$ mice.

Ectopic $\mathrm{KIT}^{\mathrm{D} 816 \mathrm{~V}}$ expression mediates expansion of fetal liver erythroid precursors and partially blocks terminal erythroid differentiation. We first mated R26-LSL-KIT ${ }^{\mathrm{D} 816 \mathrm{~V}}$ females with Sox2-Cre male mice. ${ }^{29}$ The Sox2 promoter 
mediates Cre expression in the epiblast, thereby activating transgene expression in the embryo proper. Reporter fluorescence and immunoblotting confirmed functional $\mathrm{KIT}^{\mathrm{D} 816 \mathrm{~V}}$ expression in embryos inheriting both transgenes (termed Sox2:KIT ${ }^{\mathrm{D} 816 \mathrm{~V}}$ (Sox2-Cre:R26-LSL-KIT ${ }^{\mathrm{D} 816 \mathrm{~V}}$ mice); Figures 1c and d). Sox2:KIT ${ }^{\mathrm{D} 816 \mathrm{~V}}$ embryos died in utero by day E14.5-E15.5 of embryonic development (data not shown). On day E14.5, enlargement of the fetal liver with increased cellularity could be observed in Sox2:KIT ${ }^{\mathrm{D} 816 \mathrm{~V}}$ embryos (Supplementary Figures 1B and C), suggesting that embryonic lethality originated from a defect in the hematopoietic system.
For further analyses, we specifically activated $\mathrm{KIT}^{\mathrm{D} 816 \mathrm{~V}}$ expression in hematopoietic cells by mating R26-LSL$\mathrm{KIT}^{\mathrm{D} 816 \mathrm{~V}}$ with Vav-iCre mice. ${ }^{30}$ Vav-iCre activity can be detected in E11.5 fetal liver cells. ${ }^{30,31}$ The GFP reporter confirmed the restriction of transgene expression to fetal liver cells of double transgenic embryos (termed Vav:KIT ${ }^{\mathrm{D} 816 \mathrm{~V}}$ (Vav-iCre:R26-LSL-KIT ${ }^{\mathrm{D} 816 \mathrm{~V}}$ mice)) from R26-LSL-KIT ${ }^{\mathrm{D} 816 \mathrm{~V}}$ : Vav-iCre matings (Figure 2a, Supplementary Figure 2A). No Vav: $\mathrm{KIT}^{\mathrm{D} 816 \mathrm{~V}}$ animals were obtained among 32 live births (Supplementary Table 4). Investigating embryonic development, most Vav:KIT ${ }^{\mathrm{D} 816 \mathrm{~V}}$ embryos were found dead at E14.5 (Table 1). E13.5, where most embryos were found alive, was a

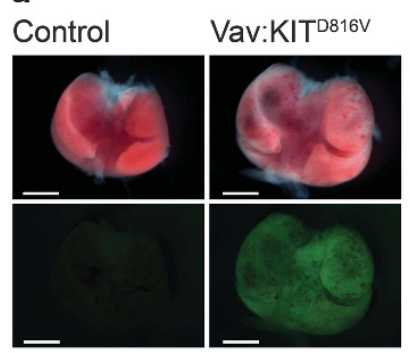

b

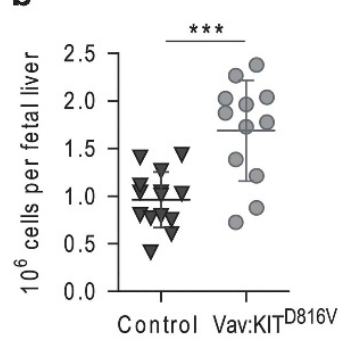

c

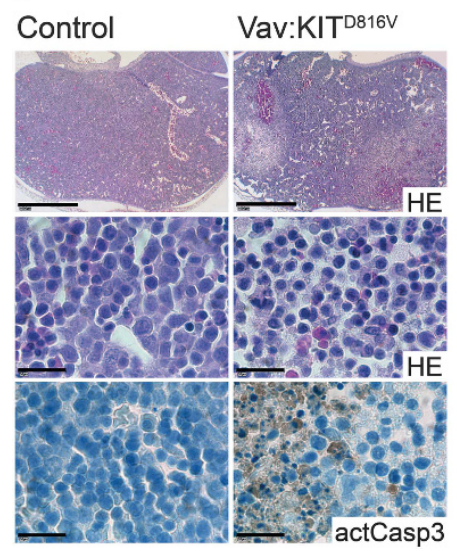

d
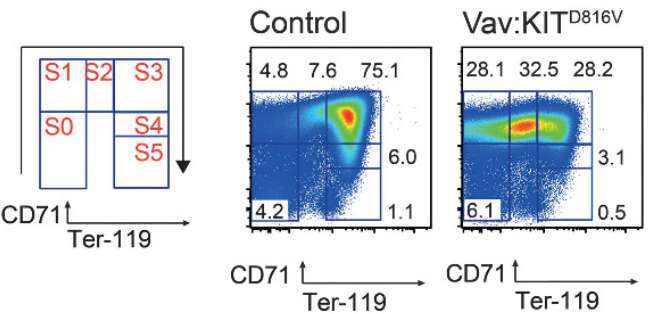

e

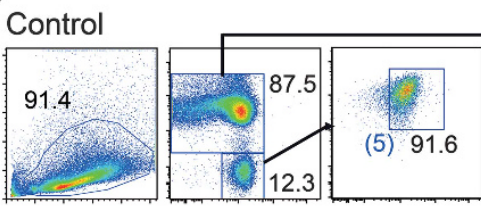

Vav:KIT ${ }^{\mathrm{D} 816 \mathrm{~V}}$
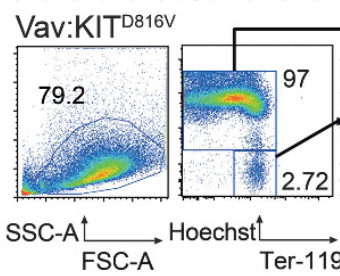

Hoechst

$r-11$

$\rightarrow \mathrm{CD} 71 \mathrm{t}$

f

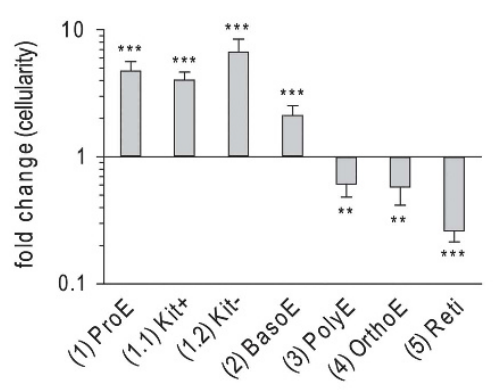

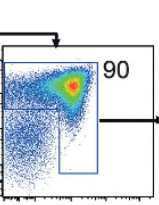

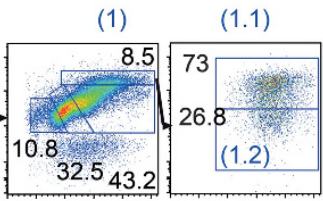

(4) (3) (2)

$\mathrm{CD} 44 \uparrow$

g



Figure 2 Accumulation of early erythroblast precursor cells in fetal liver of $\mathrm{KIT}^{\mathrm{D} 816 \mathrm{~V}}$ mutant mice. (a) R26-LSL-KIT ${ }^{\mathrm{D} 816 \mathrm{~V}}$ mice were mated to Vav-iCre mice to induce ectopic $\mathrm{KIT}^{\mathrm{D} 816 \mathrm{~V}}$ in hematopoietic cells. Pictures show fetal livers from E13.5 control embryos and embryos expressing KIT ${ }^{\mathrm{D} 16 \mathrm{~V}}$, latter indicated by GFP reporter fluorescence. Scale bar: $1 \mathrm{~mm}$. (b) Cellularity of E13.5 fetal livers. Vav:KIT ${ }^{\mathrm{D} 16 \mathrm{~V}}: N=12$. Controls: $N=14$. (c) Morphological appearance of E13.5 fetal liver tissue in hematoxylin and eosin staining of embryo transversal sections in low (top) and high magnification (middle). Immunohistochemical staining of active caspase 3 (bottom). Scale bar: $1 \mathrm{~mm}$ (top) and $20 \mu \mathrm{m}$ (middle, bottom). (d) Staging of E13.5 fetal liver cells based on CD71/Ter119 expression. Mac $1^{\text {neg }}$ B220 $0^{\text {neg }}$ cells were gated for analysis. (e) Gating strategy for flow cytometric analysis of erythropoiesis beginning from ProE stage. Black numbers indicate cell frequencies in relation to parent gate. Gates numbered in blue define erythroid cells in successive stages of differentiation and are quantified and named in $(\mathbf{f})$. ( $f$ and $\mathbf{g}$ ) Graphs show fold change in total cellularity for Vav:KIT ${ }^{\mathrm{D} 16 \mathrm{~V}}$ animals in relation to controls in log10 scale. Variance is presented as standard deviation. $P$-values were determined using a two-tailed, unpaired Student's $t$-test; ${ }^{*} P<0.05 ;{ }^{* \star} P<0.01 ;{ }^{* * \star} P<0.001$. (f) Vav:KIT ${ }^{\mathrm{B} 816 \mathrm{~V}}: N=4$. Controls: $N=4$. Kit+: Kit ${ }^{\text {pos }}$ ProEs; Kit-: Kit ${ }^{\text {neg }}$ ProEs; BasoE, basophilic erythroblast; OrthoE, orthochromatic erythroblast; PolyE, polychromatic erythroblast; Reti: reticulocyte. (g) Vav: $\mathrm{KIT}^{\mathrm{D} 816 \mathrm{~V}}: N=7$. Controls: $N=9$ 
Table 1 E14.5 analysis of embryos from Vavi-Cre $x$ R26-LSL-KIT ${ }^{\text {D816V }}$ crosses

\begin{tabular}{lcc}
\hline Genotype & \multicolumn{2}{c}{ Offspring $(\boldsymbol{n}=\mathbf{3 4})$} \\
\cline { 2 - 3 } & Viable & Dead \\
\hline Vav:KITD816V & 1 & 9 \\
R26-LSL-KIT & 10 & 0 \\
Vav-iCre & 7 & 0 \\
Wild-type & 7 & 0 \\
\hline
\end{tabular}

chosen for analyses. We observed a 1.75 -fold increase in cellularity of E13.5 Vav:KIT ${ }^{\mathrm{D} 816 \mathrm{~V}}$ livers compared with wildtype or single transgenic controls (Figure $2 b$ ). Histologically, Vav:KIT ${ }^{\mathrm{D} 816 \mathrm{~V}}$ fetal liver tissue showed areas with expansion of erythroid cells and disruption of tissue integrity. Staining against active caspase 3 revealed large apoptotic areas (Figure 2c).

To analyze fetal liver erythropoiesis, we used a flow cytometric assay based on CD71 and Ter119 expression. ${ }^{32,33}$ CD71 is expressed in committed erythroid progenitor cells and becomes downregulated in terminally differentiated cells, which upregulate Ter119. According to their CD71/Ter119 profile, cells were divided into six subsets (S0-S5), which constitute a developmental sequence in red blood cell maturation (Figure 2d). ${ }^{32,33}$ In Vav:KIT ${ }^{\mathrm{D} 816 \mathrm{~V}}$ embryos, the cells clustered predominantly to subsets S0-S2, whereas in control animals the majority of cells had progressed to S3 stage (Figure 2d, Supplementary Figure 2B). Similar results were found for Sox2:KIT ${ }^{\text {D816V }}$ embryos (Supplementary Figures 1D and E). To further define the differences in the developmental sequence, we adapted a high-resolution flow cytometric analysis for late erythroid precursors beginning from the proerythroblast (ProE) stage, ${ }^{34}$ with the gating strategy outlined in Figure $2 e$. Figure $2 f$ shows the quantified data as fold change in cellularity compared with control. This approach revealed that cells up to the basophilic erythroblast stage accumulate in Vav:KIT ${ }^{\mathrm{D} 816 \mathrm{~V}}$ fetal livers, whereas more mature cells are significantly decreased. To verify proper analysis, we sorted cells from the indicated populations and confirmed staging by morphological analysis (Supplementary Figure 2D). Of note, we also noticed a significant increase in $\mathrm{B}_{2} 20^{\text {pos }}$ and Mac- $1^{\text {pos }}$ cells in fetal livers of Vav:KIT ${ }^{\mathrm{D} 816 \mathrm{~V}}$ embryos (Figure $2 \mathrm{~g}$ ). We further determined the cell count in peripheral blood from E13.5 Vav: $\mathrm{KIT}^{\mathrm{D} 816 \mathrm{~V}}$ and control embryos. We found a mild decrease in total cellularity (not significant) and a significant decrease in the frequency of enucleated red blood cells (Supplementary Figure 2E). This indicates unaffected primitive erythropoiesis, whereas blockage of definitive erythropoiesis results in a mild anemia. Thus, ectopic Kit signaling causes marked expansion of erythroid precursors and concomitant block in terminal differentiation.

We performed transcriptome microarray analysis with E13.5 Vav:KIT ${ }^{\mathrm{D} 816 \mathrm{~V}}$ and control fetal livers and found 1523 genes differentially expressed (log2 fold change >0.5; adjusted $P$-value $<0.05)$. Array data were validated by qRT-PCR (Supplementary Figure 2F). Numerous genes relating to liver-specific metabolic processes were downregulated in accordance with liver damage observed in $\mathrm{KIT}^{\mathrm{D} 816 \mathrm{~V}}$ animals. This indicates that expansion of fetal liver erythroblasts impairs associated hepatoblasts and normal liver function, contributing to embryonic death. Supplementary Tables 5-7 provide a mapping to GO terms and KEGG pathways and a list of deregulated genes associated with apoptosis, cell cycle and erythropoiesis.

$\mathrm{KIT}^{\mathrm{D} 816 \mathrm{~V}}$ causes elevated late stage apoptosis and partially blocks cell cycle exit during Epo-dependent terminal maturation of primary erythroblasts. To further characterize the developmental block in $\mathrm{KIT}^{\mathrm{D} 816 \mathrm{~V}}$ erythroblasts, we analyzed differentiation of primary erythroblasts ex vivo. Cells from E13.5 fetal liver of Vav:KIT ${ }^{\mathrm{D} 816 \mathrm{~V}}$ and control embryos were cultured up to 5 days in serum-free medium supplemented with SCF, Epo and dexamethasone (Dex) to expand ProEs and restrict their differentiation. ${ }^{35,36}$ Under proliferative conditions, the majority of cells for either genotype were in early erythroblast stages (Supplementary Figure $3 \mathrm{~A}$ ). In order to exclude contamination with other cell types, we applied the flow cytometric analysis presented in Figure $2 \mathrm{e}$ and sorted the ProE population for subsequent analyses. Next, terminal differentiation of sorted ProEs was induced by withdrawal of SCF/Dex and administration of transferrin, insulin and Epo (high concentration) and cultures were observed for 5 days. Developmental staging of cells by morphology and hemoglobin accumulation showed that on day 3 of differentiation $>60 \%$ of control cells were enucleated and no ProEs were found. In contrast, $>20 \%$ ProEs and only $25 \%$ reticulocytes were found in $\mathrm{KIT}^{\mathrm{D} 816 \mathrm{~V}}$ cultures. On day 5 , over $90 \%$ of control cells were enucleated, while composition of $\mathrm{KIT}^{\mathrm{D} 816 \mathrm{~V}}$ cultures remained similar to day 3 (Figure 3a). As differentiation is accompanied by decreasing cell size, we performed flow cytometric forward scatter analysis. Although control cells uniformly displayed progressive cell size decrease, a fraction of $\mathrm{KIT}^{\mathrm{D} 816 \mathrm{~V}}$ cells did not decrease in size (Figure 3b). Analysis of CD71/Ter119 expression further confirmed the impaired differentiation of $\mathrm{KIT}^{\mathrm{D} 816 \mathrm{~V}}$ cells (Figure 3c, Supplementary Figure 3B).

To investigate cell death, we performed combined AnnexinV/7-aminoactinomycin staining, which revealed significantly elevated rates of apoptosis for $\mathrm{KIT}^{\mathrm{D} 816 \mathrm{~V}}$ cells after 2 and 3 days (Figure $3 d$ ). We further analyzed cell cycle distribution by staining with propidium iodide, revealing no difference in cell cycle in $\mathrm{KIT}^{\mathrm{D} 816 \mathrm{~V}}$ and control ProEs under proliferative conditions (Figure 3e). However, upon differentiation, control cells rapidly underwent cell cycle arrest and analysis was only possible until day 2 , as mostly enucleated cells were left thereafter. In contrast, significantly more $\mathrm{KIT}^{\mathrm{D} 816 \mathrm{~V}}$ cells remained in S phase on day 2 (Figure $3 \mathrm{e}$ ) and a fraction of cells continued cycling. During this experiment, growth of cells with precursor cell morphology was observed in $\mathrm{KIT}^{\mathrm{D} 816 \mathrm{~V}}$ samples (Figure 3a), which continued to proliferate for several days. We therefore asked if $\mathrm{KIT}^{\mathrm{D} 816 \mathrm{~V}}$ cells could proliferate in the absence of SCF. Here, $\mathrm{KIT}^{\mathrm{D} 816 \mathrm{~V}}$ cells could still expand to a similar level as SCF-simulated control cells. Addition of SCF considerably extended the proliferative window of $\mathrm{KIT}^{\mathrm{D} 816 \mathrm{~V}}$ cells by 3-4 days (Supplementary Figure $3 \mathrm{C}$ ). This demonstrates that transgenic $\mathrm{KIT}^{\mathrm{D} 816 \mathrm{~V}}$ signaling on its own mimics exogenous SCF stimulation in terms of cellular response (stimulation of proliferation). Our results show that $\mathrm{KIT}^{\mathrm{D} 816 \mathrm{~V}}$ erythroblasts react to differentiation 
a
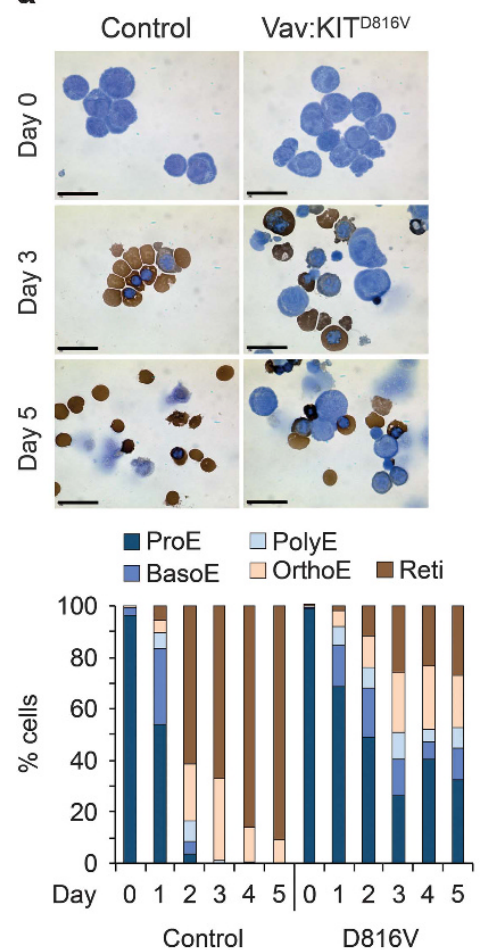

b

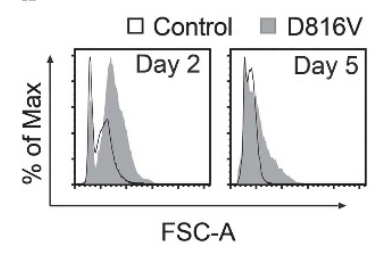

c
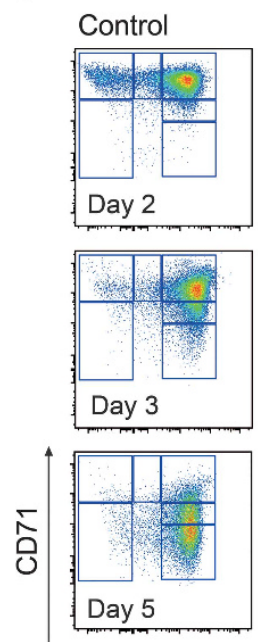

D816V
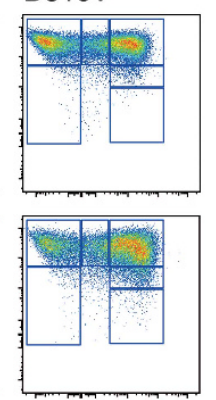

Ter119 d


e



Figure 3 Cultured primary $\mathrm{KIT}^{\mathrm{D} 816 \mathrm{~V}}$ erythroblasts exhibit sustained proliferation and a partial block in terminal differentiation. Primary erythroblasts were isolated from E13.5 Vav:KIT ${ }^{\mathrm{D} 16 \mathrm{~V}}$ and control fetal livers, expanded in culture and flow cytometric cell sorting was performed to isolate the ProE population. ProEs were then stimulated to terminally differentiate in presence of insulin and high Epo concentrations. (a) Cytospin preparations of undifferentiated cells (day 0 ) and cells from day 3 and day 5 of differentiation. Cell hemoglobin is visualized by histochemical staining of heme groups with diaminobenzidine. Counterstaining was performed with Giemsa. Scale bars: $20 \mu \mathrm{m}$. Diagram shows quantification of differentiation stages according to morphology and hemoglobin content. At least 100 cells from random visual fields were counted for each sample. Vav:KIT ${ }^{\mathrm{D} 816 \mathrm{~V}}$ : $N=3$. Controls: $N=3$. BasoE, basophilic erythroblast; OrthoE, orthochromatic erythroblast; PolyE, polychromatic erythroblast; Reti, reticulocyte. (b) Histogram overlay showing forward scatter analysis of KIT ${ }^{\mathrm{D} 16 \mathrm{~V}}$ and control cells, gated on the AnnexinV-negative fraction. (c) Staging of cells based on flow cytometric analysis of CD71/Ter119 expression. (d) The frequency of apoptosis was determined as the fraction of AnnexinV-positive cells. 7-Aminoactinomycin (7AAD) staining was used to exclude dead cells from analysis. Representative flow cytometric panels for day 2 and quantification for days $1-3$ are shown. Vav:KIT ${ }^{\mathrm{D} 16 \mathrm{~V}}: N=3$. Controls: $N=3$. (e) Cell cycle distribution was determined using propidium iodide staining. Quantification of cells in G1, S and G2 phase was done using Dean-Jet-Fox algorithm in FlowJo software. Vav:KIT ${ }^{\mathrm{D} 816 \mathrm{~V}}: N=3$. Controls: $N=3$. Variance given as S.D. $P$-values were determined using a two-tailed, unpaired Student's $t$-test; ${ }^{*} P<0.05 ;{ }^{* *} P<0.01 ;{ }^{* * *} P<0.001$

stimuli with elevated rates of apoptosis and sustained Kit signaling interferes with Epo-dependent terminal maturation. Continued cycling of KIT ${ }^{\mathrm{D} 816 \mathrm{~V}}$ cells further substantiates the well-known role of Kit signaling for proliferation of precursor cells.

$\mathrm{KIT}^{\mathrm{D} 816 \mathrm{~V}}$ erythroblasts fail to execute the transcriptional differentiation program. We next investigated the molecular mechanisms underlying the impaired differentiation capacity of $\mathrm{KIT}^{\mathrm{D} 816 \mathrm{~V}}$ erythroblasts. We analyzed transcription of genes important for erythropoiesis, cell cycle control and apoptosis in primary erythroblasts. Figure 4 a shows expression profiles for selected transcripts during differentiation of sorted ProEs. In $\mathrm{KIT}^{\mathrm{D} 816 \mathrm{~V}}$ and control ProEs (day 0), we found similar expression levels for most analyzed genes. Interestingly, expression levels for Gata2 were significantly elevated in $\mathrm{KIT}^{\mathrm{D} 816 \mathrm{~V}}$ ProEs, indicating that Kit signaling positively regulates Gata2. When cells were stimulated to differentiate, significant differences in expression dynamics were observed. Expression of Gata2, $c-M y b$ and $c-M y c$ was maintained at significantly higher levels in KIT ${ }^{\mathrm{D} 816 \mathrm{~V}}$ cells compared with controls (Figures 4a and b), whereas erythroid transcription factors Klf1, Tal1 and Gata1 were not induced properly (Figure 4a). We also found elevated CyclinD2 and reduced Cdkn1a/p21 expression in $\mathrm{KIT}^{\mathrm{D} 816 \mathrm{~V}}$ cells. Moreover, anti-apoptotic $B c / 2 / 1 / \mathrm{Bcl}-\mathrm{xL}, \mathrm{Mcl}$, Trib3 and pro-apoptotic Nix (coexpressed with $B c l-x L$ during erythroid maturation) were not upregulated in $\mathrm{KIT}^{\mathrm{D} 816 \mathrm{~V}}$ cells (Figures $4 \mathrm{a}$ and $\mathrm{b}$, Supplementary Figure 4A). ${ }^{21,37-40}$ Alongside, downregulation of Bad and Bid was impaired (Figure 4a). These data show that continuous Kit signaling perturbs induction of the transcriptional program associated with terminal erythroid maturation and interferes with regulation of key mediators of cell cycle control, cell death and survival, thereby leading to continued proliferation and elevated apoptosis during terminal differentiation.

As we found a failure of $\mathrm{KIT}^{\mathrm{D} 816 \mathrm{~V}}$ cells to undergo the switch from GATA-2 to GATA-1 expression, we asked if overexpression of erythroid master regulator GATA-1 would rescue differentiation of $\mathrm{KIT}^{\mathrm{D} 816 \mathrm{~V}}$ cells. We retrovirally transduced primary KIT ${ }^{\mathrm{D} 816 \mathrm{~V}}$ cells with MSCV-GATA-1-mCherry and induced terminal differentiation. However, we found no 
a
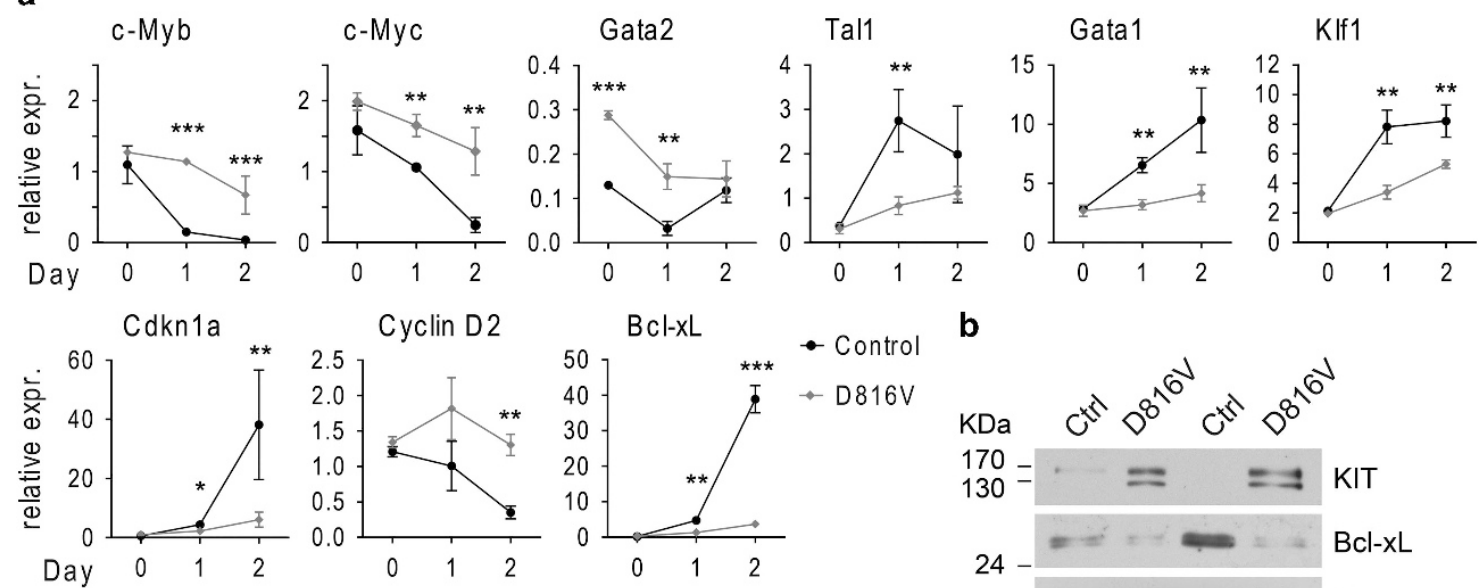

b
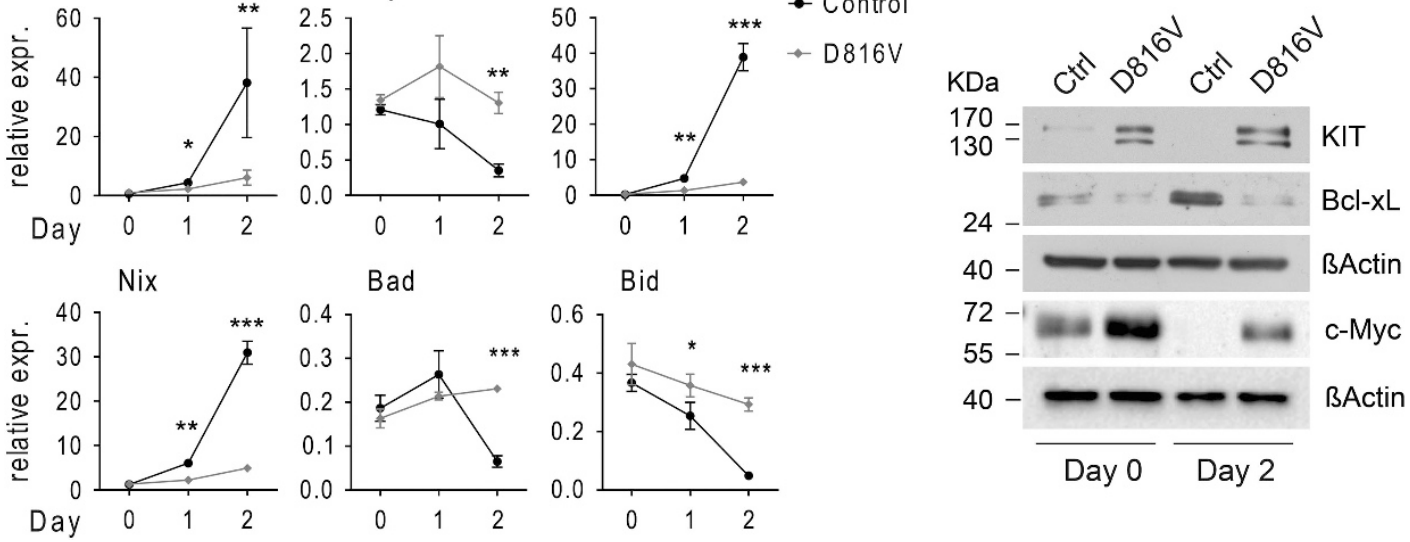

Bid

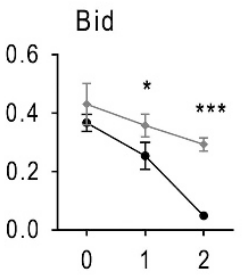

Figure $4 \quad \mathrm{KIT}^{\mathrm{D} 816 \mathrm{~V}}$ erythroblasts fail to establish the erythroid transcriptional differentiation program and to induce key mediators for cell survival and cell cycle exit. (a) Primary erythroblasts from E13.5 fetal livers were expanded and sorted for ProEs by flow cytometry. Cells were then stimulated to terminally differentiate in presence of insulin and high Epo concentrations. Transcription levels of indicated genes were determined by qRT-PCR. Shown is the relative expression normalized to Gusb and Sdha. Vav:KITD816V: $N=3$. Controls: $N=3$. Variance given as S.D. $P$-values were determined using a two-tailed, unpaired Student's $t$-test; ${ }^{*} P<0.05 ;{ }^{* \star} P<0.01 ;{ }^{* \star *} P<0.001$. (b) Primary erythroblasts were expanded and stimulated to differentiate. Protein was isolated from undifferentiated cells (day 0 ) and cells on day 2 of differentiation and used for immunoblot analysis of indicated proteins

difference in differentiation or gene expression in comparison with empty-vector controls (Supplementary Figures 4D-F), demonstrating that GATA-1 is not sufficient to overcome the $\mathrm{KIT}^{\mathrm{D} 816 \mathrm{~V}}$-mediated differentiation block.

$\mathrm{KIT}^{\mathrm{D} 816 \mathrm{~V}}$ leads to constitutive activation of p42/44 MAPK and modulates Akt activation in response to Epo. In our transcription analyses, we noted failed induction of the EpoR/Stat5 targets Cis, ${ }^{41}$ Socs $3,{ }^{42}$ and $\mathrm{Bcl}-x \mathrm{~L}^{5,43}$ in differentiating $\mathrm{KIT}^{\mathrm{D} 816 \mathrm{~V}}$ cells (Figure $4 \mathrm{a}$, Supplementary Figure $4 \mathrm{C}$ ), and that prompted us to investigate EpoR signaling. We starved KIT ${ }^{\mathrm{D} 816 \mathrm{~V}}$ and control erythroblasts of cytokines for $4 \mathrm{~h}$, stimulated them with SCF or Epo and analyzed activity of key signaling molecules by immunblotting. In the absence of cytokine stimuli, phosphorylation of p42/44 MAPK was evident in $\mathrm{KIT}^{\mathrm{D} 816 \mathrm{~V}}$ cells, indicating constitutive MAPK signaling. Interestingly, Epo-induced Stat5 phosphorylation was comparable between $\mathrm{KIT}^{\mathrm{D} 816 \mathrm{~V}}$ and control cells. Instead, we detected slightly lower levels of p42/44 phosphorylation and strong hypophosphorylation of Akt in $\mathrm{KIT}^{\mathrm{D} 816 \mathrm{~V}}$ cells upon Epo stimulation (Figure 5a). Akt phosphorylation in mutant cells was also lower in response to SCF when compared with controls. The reduced Akt response may be explained by $\mathrm{KIT}^{\mathrm{D} 816 \mathrm{~V}}$-induced feedback mechanisms, which may render cells unresponsive for differentiation-inducing signals transduced by EpoR.

Interfering with MAPK activation partially restores terminal differentiation of $\mathrm{KIT}^{\mathrm{D} 816 \mathrm{~V}}$ erythroblasts. Constitutive p42/44 phosphorylation pointed to a critical role of the MAPK pathway in $\mathrm{KIT}^{\mathrm{D} 816 \mathrm{~V}}$-mediated inhibition of terminal erythroid differentiation. To confirm functional importance of this pathway, we interfered with MAPK activity by adding the MEK1/2 inhibitor U0126 during erythroblast differentiation. On days 2 and 3, a partial rescue of differentiation of U0126treated $\mathrm{KIT}^{\mathrm{D} 816 \mathrm{~V}}$ erythroblasts could be demonstrated by morphological staging (Figure 5b) and CD71/Ter119 expression, which showed significantly less $\mathrm{KIT}^{\mathrm{D} 816 \mathrm{~V}}$ cells in S2 and more in S4 stage (Figure 5c, Supplementary Figure 5B). Moreover, U0126-treated $\mathrm{KIT}^{\mathrm{D} 816 \mathrm{~V}}$ cells showed initiation of Klf1 expression and repression of $c-M y b$ and $c-M y c$ (Figure 5d). However, MEK1/2 inhibition had also an effect on CD71/Ter119 expression in control cells. Here, we found a shift from S5 toward S3 and S4 stages in U0126-treated cells (Supplementary Figure 5A). Accordingly, on day 5 we no longer detected a significant difference between $\mathrm{KIT}^{\mathrm{D} 816 \mathrm{~V}}$ cells treated with solvent and U0126 (Supplementary Figure $5 \mathrm{C})$. These results might indicate that Kit-dependent MAPK activity counteracts initiation of terminal maturation, while it also has an important role in the later, final erythroid maturation steps, possibly in the context of EpoR signaling.

SFK member Lyn is deregulated in $\mathrm{KIT}^{\mathrm{D816V}}$ erythroblasts. SFK member Lyn has been reported to mediate Kit and EpoR signaling in erythroid cells. ${ }^{16,44}$ Owing to its key role, we assessed the activity of Lyn and found increased activating (Y396) and inhibitory phosphorylation (Y507) in $\mathrm{KIT}^{\mathrm{D} 816 \mathrm{~V}}$ cells compared with controls, indicating an elevated 
a

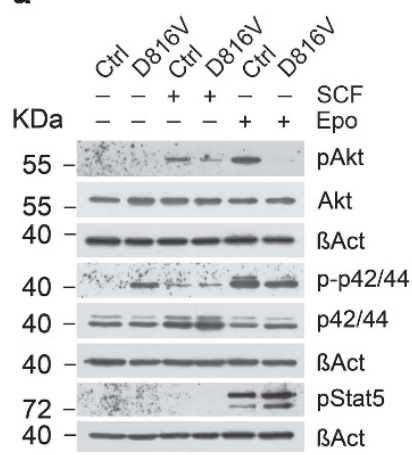

b

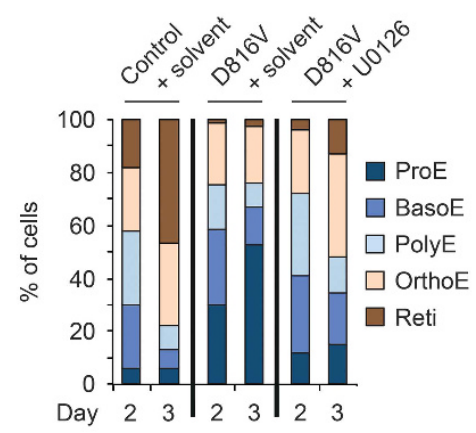

c

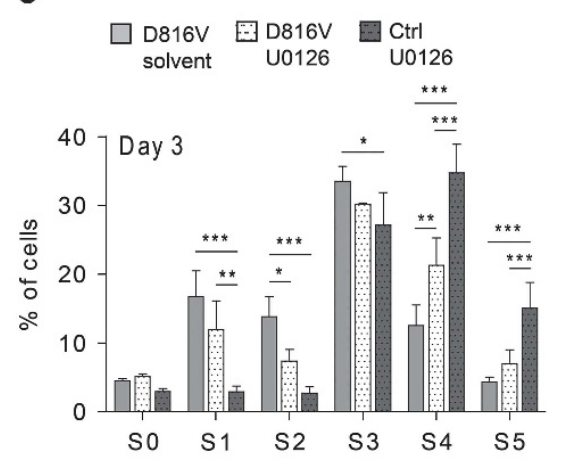

d

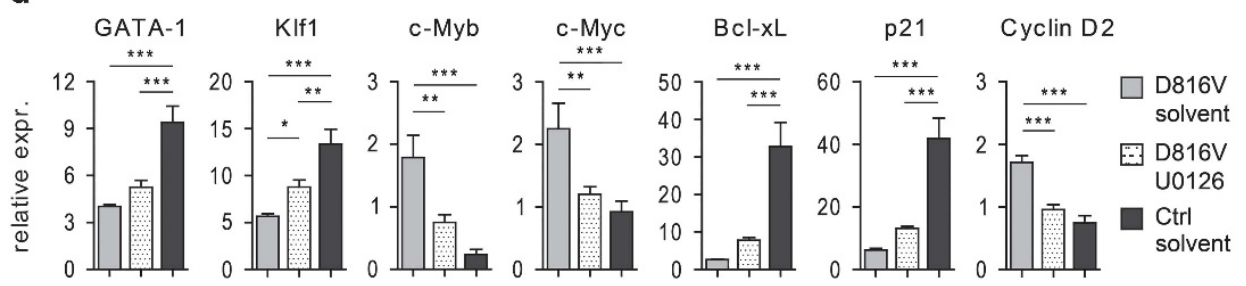

Figure 5 Constitutive MAPK pathway activation contributes to the $\mathrm{KIT}^{\mathrm{D} 816 \mathrm{~V}}$-induced block in differentiation. (a) Primary erythroblast cells were cytokine-starved for $4 \mathrm{~h}$ and stimulated for $10 \mathrm{~min}$ with $1 \mu \mathrm{g} / \mathrm{ml} \mathrm{SCF}$ or 10 units/ml Epo as indicated. Cells were then lysed to analyze activity of key signaling molecules by immunoblotting. Results shown are representatives of three independent experiments. (b-d) Erythroblast cells were stimulated to differentiate in the presence of MEK1/2 inhibitor U0126 (10 $\mu \mathrm{M})$ or DMSO as solvent control. (b) Cells were staged according to morphology and hemoglobin accumulation. Vav:KIT ${ }^{\mathrm{D} 16 \mathrm{~V}}: N=3$. Controls: $N=3$. BasoE, basophilic erythroblast; OrthoE, orthochromatic erythroblast; PolyE, polychromatic erythroblast; Reti, reticulocyte. (c) Cells were analyzed by flow cytometry and staged according to their CD71/Ter119 expression profile. Graph shows quantification for day 3 of differentiation. Statistical analysis was performed by means of two-way ANOVA with Bonferroni post-tests. (d) Relative expression levels of indicated genes determined by qRT-PCR on day 2 of differentiation in KIT ${ }^{\mathrm{D} 816 \mathrm{~V}}$ cells treated with $\mathrm{U} 0126$ and corresponding solvent controls (normalized to Gusb and Sdha). Vav:KIT ${ }^{\mathrm{D} 816 \mathrm{~V}}: N=3$. Controls: $N=3 ; P$-values were determined using one-way ANOVA with Bonferroni post-tests. Variance given as S.D. ${ }^{*} P<0.05 ;{ }^{* *} P<0.01$; ${ }^{* * \star} P<0.001$

activity with increased feedback inhibition. We also found increased expression of Lyn on protein and transcript level in $\mathrm{KIT}^{\mathrm{D} 816 \mathrm{~V}}$ cells (Figure 6a). To investigate the influence of SFK on erythroid differentiation, we treated cells with Dasatinib, a potent $\mathrm{Src} / \mathrm{Abl}$ and Kit inhibitor. ${ }^{45}$ Interestingly, Dasatinib accelerated differentiation of control cells, showing the important function of Kit and $\mathrm{Src}$ in preventing premature erythroblast differentiation. Dasatinib fully restored differentiation of $\mathrm{KIT}^{\mathrm{D} 816 \mathrm{~V}}$ cells (Figures $6 \mathrm{~b}$ and $\mathrm{c}$, Supplementary Figure 5D). As Dasatinib lacks specificity for SFKs, we treated cells with the SFK-specific inhibitor SU6656. ${ }^{46}$ Under proliferative conditions SU6656 had an inhibitory effect on erythroblast proliferation, which became obvious earlier in control cells (Figure 6d). However, we could not observe consistent inhibition of SCF-induced active Lyn or p42/44 phosphorylation upon SU6656 administration in the indicated concentrations (Supplementary Figure 5E). Accordingly, we found no effect of SU6656 on terminal differentiation of $\mathrm{KIT}^{\mathrm{D} 816 \mathrm{~V}}$ cells (Supplementary Figures $5 \mathrm{~F}$ and $\mathrm{G}$ ). Further studies will be necessary to elucidate the role of Lyn in $\mathrm{Kit} / \mathrm{EpoR}$ co-signaling and the differentiation block of $\mathrm{KIT}{ }^{\mathrm{D} 816 \mathrm{~V}}$ cells.

Taken together, our data demonstrate that Kit-induced MAPK activity antagonizes the first steps of erythroblast differentiation. Administration of Dasatinib indicates that other signaling transducers, potentially SFK member Lyn, must act in parallel to MAPK to exert the full inhibitory effect of $\mathrm{KIT}^{\mathrm{D} 816 \mathrm{~V}}$ on differentiation.

\section{Discussion}

Stimulation of Kit by SCF has been shown to promote proliferation and delay differentiation of hematopoietic precursor cells. ${ }^{8}$ The mechanisms that mediate cellular response downstream of Kit signaling and modulate cell differentiation are still incompletely understood. We generated a mouse model that allows ectopic expression of autoactive Kit ${ }^{\mathrm{D} 816 \mathrm{~V}}$ during fetal liver hematopoiesis. Although mechanisms of autoactive $\mathrm{Kit}^{\mathrm{D} 816 \mathrm{~V}}$ signaling cannot be formally equated with physiological mechanisms triggered by SCF in erythropoiesis, their study can provide valuable insights into those processes as basis for further investigation. Furthermore, a mouse model for $\mathrm{Kit}^{\mathrm{D} 816 \mathrm{~V}}$ expression is of great interest for the study of Kit receptor mutations in hematologic malignancies. In Kit ${ }^{\mathrm{D} 816 \mathrm{~V}}$ mice, we found marked expansion of committed erythroid precursors and inhibition of their terminal differentiation, characterized by suppression of the transcriptional differentiation program and deregulation of apoptotic regulators like $\mathrm{Bcl}-\mathrm{xL}$.

In primary $\mathrm{KIT}^{\mathrm{D} 816 \mathrm{~V}}$ erythroblasts stimulated to differentiate, we noted retained expression of precursor cell associated transcription factors GATA-2, c-Myb and c-Myc and insufficient expression of the erythroid master regulator GATA-1. Different studies have shown that ectopic expression of either GATA-2, c-Myb or c-Myc leads to an arrest in terminal erythroid differentiation, ${ }^{47-49}$ resembling the partial block seen in $\mathrm{KIT}^{\mathrm{D} 816 \mathrm{~V}}$ cells. Hence, our data strongly suggest that Kit signaling positively regulates expression of these factors, which each affect terminal differentiation. Overexpression of a 
a

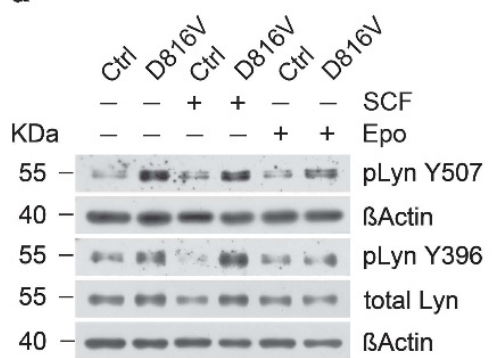

b

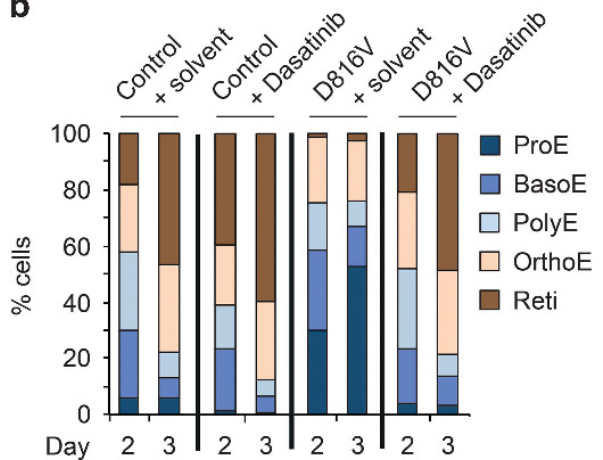

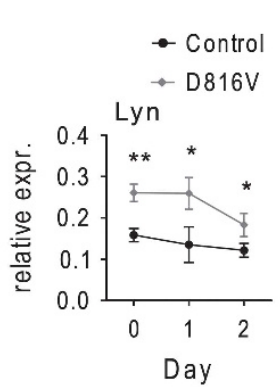

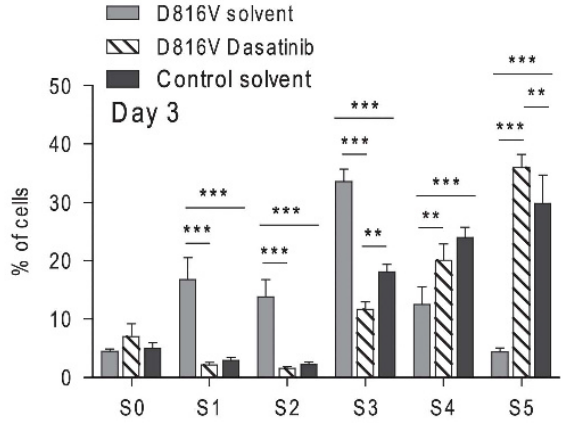

d

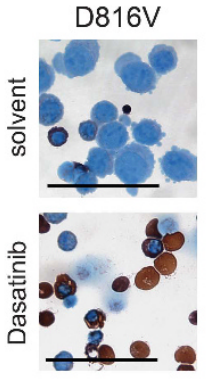

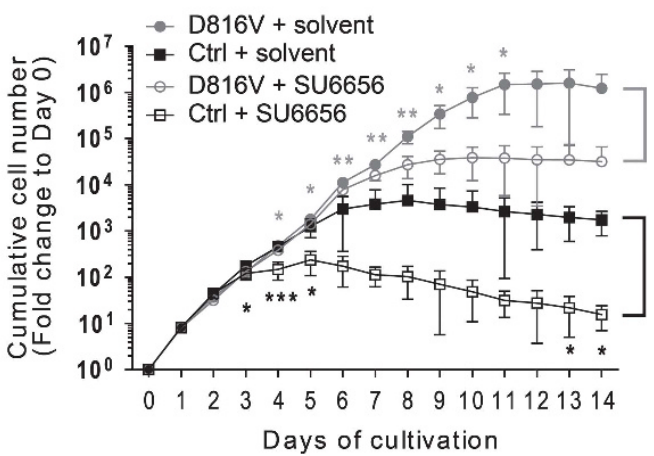

Figure 6 SFK member Lyn shows elevated expression and hyperactivation in $\mathrm{KIT}^{\mathrm{D} 816 \mathrm{~V}}$ erythroblasts. (a) Left: primary erythroblast cells were cytokine-starved for $4 \mathrm{~h}$ and stimulated for $10 \mathrm{~min}$ with $1 \mu \mathrm{g} / \mathrm{ml} \mathrm{SCF}$ or 10 units/ml Epo as indicated. Immunoblotting was performed to analyze the activity of SFK member Lyn. Results shown are representatives of three independent experiments. Right: relative expression levels of Lyn in KIT ${ }^{\mathrm{D} 816 \mathrm{~V}}$ and control cells were determined by qRT-PCR (normalized to Gusb and Sdha). Vav:KIT ${ }^{\mathrm{D} 16 \mathrm{~V}}: N=3$. Controls: $N=3$. $P$-values were determined using a two-tailed, unpaired Student's $t$-test. (b and $\left.\mathbf{c}\right)$ Erythroblast cells were stimulated to differentiate in the presence of Dasatinib $(500 \mathrm{nM})$ or DMSO as solvent control. (b) Cells were staged according to morphology and hemoglobin accumulation. Vav:KIT ${ }^{\mathrm{D} 816 \mathrm{~V}}: \mathrm{N}=3$. Controls: $N=3$. Pictures show diaminobenzidine/Giemsa staining of KIT ${ }^{\mathrm{D} 816 \mathrm{~V}}$ cells on day 3 of differentiation in presence of DMSO (solvent) or Dasatinib. Scale bars: $50 \mu \mathrm{m}$. BasoE, basophilic erythroblast; OrthoE, orthochromatic erythroblast; PolyE, polychromatic erythroblast; Reti, reticulocyte. (c) Staging of cells based on flow cytometric analysis of CD71/Ter119 expression. Graph shows quantification for day 3 of differentiation. Vav:KIT ${ }^{\mathrm{D} 16 \mathrm{~V}}: N=3$. Controls: $N=3$. Statistical analysis was performed by two-way ANOVA with Bonferroni post-tests. (d) Primary erythroblast cells were grown under proliferation conditions with SCF and Epo in the presence of either SFK inhibitor SU6656 (2 $\mu \mathrm{M}$ ) or DMSO as solvent control. The cumulative cell number was determined for 14 days and normalized to day 0. Data shown in log 10 scale. Note that S.D. for some data points cannot be depicted in log scale as negative values cannot be shown. For statistical analysis, $P$-values were pairwise determined for DMSO versus SU6656-treated control and Vav:KIT ${ }^{\mathrm{D} 816 \mathrm{~V}}$ cultures (two-tailed, unpaired Student's $t$-test), respectively. Vav:KIT ${ }^{\mathrm{D} 816 \mathrm{~V}}$ : $N=4$. Controls: $N=4$. Variance given as S.D.; ${ }^{\star} P<0.05 ;{ }^{* \star} P<0.01 ;{ }^{* \star \star} P<0.001$

dominant-negative $c-M y c$ and $c-M y b$ might be a useful approach to investigate their functional contribution to the phenotype of $\mathrm{KIT}^{\mathrm{D} 816 \mathrm{~V}}$ cells.

GATA-2, c-Myb and c-Myc are directly repressed by GATA-1. ${ }^{50-52}$ Thus, elevated levels of these factors in KIT ${ }^{\mathrm{D} 816 \mathrm{~V}}$ cells might also be a consequence of GATA-1 deficiency. However, overexpression of GATA-1 in $\mathrm{KIT}^{\mathrm{D} 816 \mathrm{~V}}$ cells was not able to restore differentiation and to induce downregulation of GATA-2, c-Myb and c-Myc. As we found significantly elevated Gata2 expression in $\mathrm{KIT}^{\mathrm{D} 816 \mathrm{~V}}$ ProEs, we speculate that GATA-2 occupancy of GATA binding sites may render $\mathrm{KIT}^{\mathrm{D} 816 \mathrm{~V}}$ cells unable to undergo the GATA switching. Interestingly, induction of GATA-2 expression by SCF/Kit signaling has been reported before. ${ }^{53}$

Upon Epo-dependent differentiation, $\mathrm{KIT}^{\mathrm{D} 816 \mathrm{~V}}$ cells underwent elevated apoptosis marked by decreased induction of anti-apoptotic factors like Bcl-xL and Mcl1. This is in accordance with previous reports studying the physiological role of SCF in erythroid survival, demonstrating SCF-mediated protection of erythroblasts from apoptosis by upregulation of $\mathrm{Bcl}-2$ family proteins. ${ }^{54}$ In addition, we found
$\mathrm{KIT}^{\mathrm{D} 816 \mathrm{~V}}$-dependent deregulation of pro-apoptotic factors like Nix, deficiency for which also impairs erythroid maturation. ${ }^{39}$ These findings substantiate and extend the role of Kit in protection from apoptosis through regulation of pro- and antiapoptotic factors.

As EpoR/Stat5 target genes Bcl-xL, Cis and Socs3 were affected in $\mathrm{KIT}^{\mathrm{D} 816 \mathrm{~V}}$ cells, we hypothesized that the Epo/Stat5 response might be impaired by continuous $\mathrm{KIT}^{\mathrm{D} 816 \mathrm{~V}}$ signaling. However, studying the short-term signaling response, we found regular Epo-dependent Stat5 phosphorylation in $\mathrm{KIT}^{\mathrm{D} 816 \mathrm{~V}}$ cells. We speculate that Stat5 signaling might act in concert with other pathways to regulate specific target genes. Stat5 associates to phosphorylated tyrosine Y343 of the EpoR, whereas PI3K can directly bind to Y479. ${ }^{55}$ However, studies using EpoR tyrosine-mutants demonstrated that $\mathrm{PI} 3 \mathrm{~K} / \mathrm{Akt}$ activation is also indirectly mediated via $\mathrm{Y} 343$, involving the adaptor Gab2. ${ }^{37,55,56}$ Stat5 and Akt pathways are thus coupled in EpoR signaling and might cooperate in target gene activation. Interestingly, we could show that $\mathrm{KIT}^{\mathrm{D} 816 \mathrm{~V}}$ cells exhibit a marked reduction of Epo-induced Akt activation. Thus, $\mathrm{KIT}^{\mathrm{D} 816 \mathrm{~V}}$ signaling does not interfere with EpoR/Stat5 
activation per se but rather modifies combined activation of signal cascades downstream of EpoR. This might explain the failed activation of EpoR/Stat5 target genes and altered cellular response. Using the MEK1/2 inhibitor U0126, we demonstrate that MAPK signaling contributes to $\mathrm{KIT}^{\mathrm{D} 816 \mathrm{~V}}$ mediated repression of erythroid differentiation. Based on our results, we propose a model where Kit-induced MAPK signaling renders cells resistant to differentiation signals elicited by EpoR, promoting the undifferentiated state of erythroblast cells. However, the detailed mechanisms by which Kit-induced MAPK signaling modulates Epo response remain to be elucidated. We suggest that downregulation of Kit signaling is a prerequisite for EpoR/Stat5/Akt governed terminal differentiation. Figure 7 schematically summarizes $\mathrm{KIT}^{\mathrm{D} 816 \mathrm{~V}}$ influences on signal transduction and gene expression observed in this study and integrates results with findings from literature.

Of note, previous mouse models with activating Kit mutations also report disturbances of the erythroid lineage. ${ }^{57,58}$ However, molecular effects have not been characterized in these models and erythropoiesis is only slightly affected compared with Vav:KIT ${ }^{\mathrm{D} 816 \mathrm{~V}}$ mice. Thus, our model might be better suited to analyze the molecular cascades following Kit activation in erythroid cells.

In summary, we established a Cre-inducible model allowing tissue-specific investigation of sustained Kit signaling. Here, we analyzed the molecular effects of Kit autoactivation during fetal liver erythropoiesis and identified MAPK signaling as an important transducer for $\mathrm{KIT}^{\mathrm{D} 816 \mathrm{~V}}$-mediated preservation of an undifferentiated state. Primary $\mathrm{KIT}^{\mathrm{D} 816 \mathrm{~V}}$ fetal liver erythroblasts provide an excellent system facilitating further studies of integrative processing of Kit and Epo transduced signals. In addition, this model enables further analysis of signaling axes demonstrated to be employed by SCF/Kit in other models, like the Notch2 signaling pathway. ${ }^{53,59}$ Finally, application of an inducible Cre line will allow studies of the $\mathrm{KIT}^{\mathrm{D} 816 \mathrm{~V}}$ mutation in hematologic malignancies of the adult.

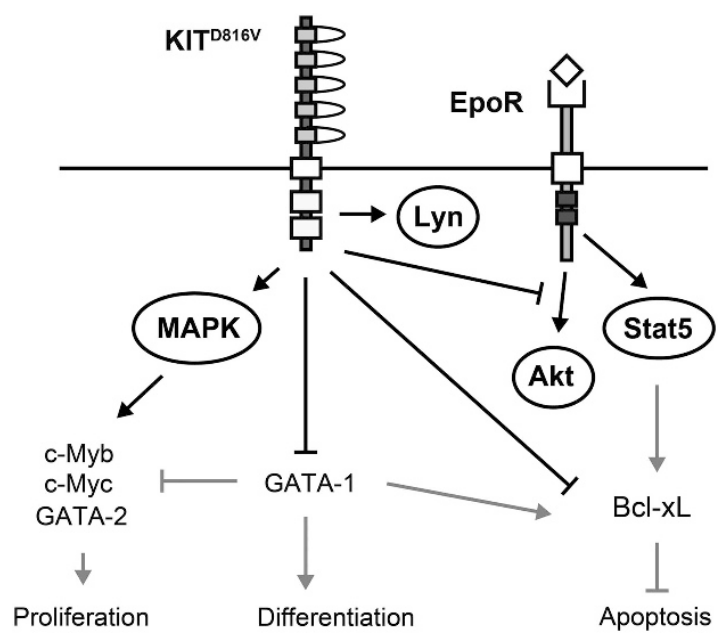

Figure 7 Schematic summary outlining the molecular mechanisms resulting in block of differentiation and sustained proliferation in $\mathrm{KIT}^{\mathrm{D} 816 \mathrm{~V}}$ erythroblasts. Black arrows show relationships uncovered in this work. Gray arrows indicate interactions/ regulations that have been demonstrated in other studies

\section{Materials and Methods}

Animals/ethics statement. All experiments were conducted according to the German law of animal protection and in agreement with the approval of the local institutional animal care committees (Landesamt für Natur, Umwelt und Verbraucherschutz, North Rhine-Westphalia (approval ID: \#8.87-50.10.31.08.238)).

Mice. $\mathrm{KIT}^{\mathrm{D} 816 \mathrm{~V}}$ CDNA, consisting of the murine extracellular and transmembrane domains and the human intracellular domain including the D816V substitution, was cloned from MIG-HyKit ${ }^{\mathrm{D} 16 \mathrm{~V}}$ (kindly provided by Zhifu Xiang and Michael $\mathrm{H}$ Tomasson, Department of Internal Medicine, St. Louis, MO, USA). We generated a GFP-2A-KIT D816V fusion construct encoding a GFP from copepod Pontellina plumata linked to $\mathrm{KIT}^{\mathrm{D} 816 \mathrm{~V}}$ by a $2 \mathrm{~A}$-peptide originating from Thosea asigna virus. ${ }^{28}$ For that, the GFP coding sequence was amplified using forward primer GFPFor (adding a Kpnl site to its 5' end) and reverse primer GFP-2A-KITRev (excluding the stop codon and adding the $2 \mathrm{~A}$ and $\mathrm{KIT}$ starting sequences). A KIT ${ }^{\mathrm{D} 16 \mathrm{~V}} \mathrm{~N}$-terminal fragment was amplified using the reverse complement to GFP-2A-KITRev as the forward primer, and KITRev as the reverse primer (introducing an artificial Xhol site downstream the endogenous KIT BamHI site). The amplicons served as templates for fusion PCR to generate the GFP-2A-KIT ${ }^{\text {Nterm }}$ fragment. The product was digested with Kpnl and Xhol and cloned into pcDNA3 (Life Technologies, Carlsbad, CA, USA). The C-terminal KIT ${ }^{\mathrm{D} 816 \mathrm{~V}}$ BamHI-Xhol fragment was ligated into this vector to generate full lenght GFP-2A-KIT ${ }^{\mathrm{D} 816 \mathrm{~V}}$. Primer sequences are given in Supplementary Table 1. To derive the pR26-LSL-KIT ${ }^{\text {D816V }}$ targeting vector the GFP-2A-KIT ${ }^{\mathrm{D} 816 \mathrm{~V}}$ cassette was inserted into the Sall site of the plasmid RPP ${ }^{60}$ that has been modified from Soriano's pROSA26-1 (ref. 61) by introduction of a splice acceptor sequence and a loxP-flanked transcriptional STOP cassette (loxP-STOPIoxP; LSL). ${ }^{60}$ pR26-LSL-KIT ${ }^{\mathrm{DB16V}}$ was introduced into 129/Ola-derived IB10 (ref.62) murine embryonic stem cells as previously described. ${ }^{60}$ Southern blot analysis verified homologous recombination at the Gt(ROSA)26Sor (ROSA26) locus and blastocyst injection yielded chimeric mice. Offspring were screened for presence of the targeted allele by PCR; primer sequences are given in Supplementary Table 1. Transgenic mice were termed R26-LSL-KIT ${ }^{\mathrm{D} 16 \mathrm{~V}}$ mice and crossed back into the 129Sv/S2 genetic background. Mice were registered with the mouse genome database (MGl:5516508), the allele is named Gt(ROSA)26sorTM1(GFP-cKIT*)Hsc. Sox2-Cre mice ${ }^{29}$ were maintained on a 129Sv/S2 genetic background and Vav-iCre mice $^{30}$ were maintained on a C57BL/6J genetic background. Imaging of mouse embryos and fetal livers was performed with a Leica MZ16 FA stereomicroscope (Leica, Wetzlar, Germany) using a Planapo 1x objective and pictures were taken with a Microfire digital camera (Optronics, Goleta, CA, USA). Analysis of fetal peripheral blood is described in Supplementary Experimental Procedures.

Flow cytometry. Fetal liver cellularity was determined using a Hemavet 950 (Drew Scientific, Dallas, TX, USA). Cells were stained with fluorochrome-conjugated antibodies listed in Supplementary Table 2. Nucleated cells were stained with $10 \mu \mathrm{g} /$ $\mathrm{ml}$ Hoechst H33342 (Life Technologies). Apoptosis was assayed using PE AnnexinV Apoptosis Detection Kit I (BD Pharmingen, San Diego, CA, USA) according to the manufacturer's instructions. For cell cycle analysis, cells were fixed in $70 \%$ ethanol, rehydrated and stained with propidium iodide. Doublets were excluded by gating in FSC-width against FSC-area plot. Flow cytometry was performed on a BD FACSCanto $^{\mathrm{TM}}$ II Flow Cytometer (Becton Dickinson, Heidelberg, Germany) and data were analyzed using FlowJo software (TreeStar, Ashland, OR, USA). Flow cytometric cell sorting was performed using a BD FACSAria III (Becton Dickinson) with $70 \mu \mathrm{m}$ nozzle size.

Transcriptome microarray analysis. For microarray-based transcriptome analysis, the Illumina MouseWG-6 v2.0 Expression BeadChip (Illumina, San Diego, CA, USA) was used. Sample processing and data analysis is described in Supplementary Experimental Procedures. Microarray data have been deposited in NCBl's Gene Expression Omnibus and are accessible through GEO Series accession number GSE53581.

Cell culture. Cultivation of primary erythroid progenitor cells was performed as described elsewhere ${ }^{35}$ with few adaptations. Briefly, fetal liver cells from E13.5 embryos were seeded in serum-free StemPro-34 medium plus nutrient supplement (Life Technologies), supplemented with $2 \mathrm{U} / \mathrm{ml}$ human recombinant erythropoietin (Erypo FS 1000, Janssen-Cilag, Neuss, Germany), $100 \mathrm{ng} / \mathrm{ml}$ murine recombinant SCF (Miltenyi Biotec, Bergisch Gladbach, Germany), $0.4 \mu \mathrm{g} / \mathrm{ml}$ Dex and $40 \mathrm{ng} / \mathrm{ml}$ mouse IGF-1 (Sigma-Aldrich, St. Louis, MO, USA). Dead and differentiated cells were removed by centrifugation through Ficoll (density $1.077 \mathrm{~g} / \mathrm{ml}$ ). For induction of 
terminal differentiation, cells were washed twice in PBS and resuspended in StemPro-34 medium with $10 \mathrm{U} / \mathrm{ml}$ human recombinant erythropoietin, $1 \mathrm{mg} / \mathrm{ml}$ iron-saturated human transferrin (Sigma-Aldrich) and $4 \times 10^{-4} \mathrm{IE} / \mathrm{ml}$ Insulin (Actrapid Flex Pen, Novo Nordisk, Bagsværd, Denmark). Dasatinib and U0126 MEK1/2 inhibitor were purchased from Cell Signaling Technology (Danvers, MA, USA) and used at a final concentration of $500 \mathrm{nM}$ and $10 \mu \mathrm{M}$, respectively. SU6656 (Santa Cruz Biotechnology, Dallas, TX, USA) was used at a final concentration of $2 \mu \mathrm{M}$. Retroviral infection of primary erythroblasts is described in Supplementary Experimental Procedures.

Quantitative real-time PCR and immunoblotting. Total RNA was isolated using RNeasy Mini Kit (Qiagen, Hilden, Germany). cDNA synthesis was performed using RevertAid Premium reverse transcriptase (Fermentas, Thermo Fisher Scientific, Waltham, MA, USA). For amplification of target sequences, Maxima SYBR Green/ROX (Fermentas) was used. Reference genes Gusb (glucuronidase), Sdha (succinate dehydrogenase) and Hprt (hypoxanthine-guanine phosphoribosyltransferase) were used for normalization. Primer sequences for qRTPCR are given in Supplementary Table 3. For protein extraction, cells were lysed in radioimmunoprecipitation assay buffer (Cell Signaling Technology) supplemented with complete mini protease inhibitor, PhosSTOP (Roche, Penzberg, Germany) and sodium orthovanadate. Antibodies for immunoblotting are listed in Supplementary Table 2.

Histology and immunohistochemistry. For immunohistochemistry, samples were fixed in $4 \%$ paraformaldehyde, dehydrated, embedded in paraffin and stained with antibodies against Ki67 (DAKO, Glostrup, Denmark), caspase 3 (cleaved) (Zytomed Systems, Berlin, Germany) and biotinylated secondary antibodies (DAKO). Imaging was performed with a Leica DM5500 B microscope using $4 \times / 0.10$ and $100 x / 1.30$ oil objectives. Pictures were taken with a JVC KY-F75U digital camera (JVC, Wayne, NJ, USA). Cytospins were prepared using a Shandon Cytospin3 cytocentrifuge (Shandon Lipshaw, Erie, PA, USA). For hemoglobin detection, slides were fixed in methanol, incubated in $0.05 \%$ 3,3'-diaminobenzidine, $1 \%$ imidazole, $0.1 \% \mathrm{H}_{2} \mathrm{O}_{2}$ in $50 \mathrm{mM}$ Tris-Hcl buffer ( $\mathrm{pH} 7.4$ ) protected from light and counterstained with Giemsa. Pictures were taken with a Leica DM LB microscope using a 100x/1.30-0.60 oil objective a JVC KY-F70B digital camera.

Statistical analysis. Data are presented as mean of independent experiments with the variance given as S.D. The statistical significance is represented by one asterisk $(P<0.05)$; two asterisks $(P<0.01)$ and three asterisks $(P<0.001)$. $P$-values were determined using a two-tailed, unpaired Student's $t$-test for comparison between two groups. For comparison between more than two groups, one-way ANOVA or two-way ANOVA with Bonferroni post-tests were performed using GraphPad Prism (GraphPad Software, San Diego, CA, USA).

\section{Conflict of Interest}

The authors declare no conflict of interest.

Acknowledgements. $\mathrm{NH}$ is supported by the Deutsche José Carreras Leukämie-Stiftung (F13/03). The experiments were supported by the Deutsche Krebshilfe (\#108249) to HS and a collaborative grant from the Kompetenznetzwerk Stammzellforschung NRW. MSCV-IRES-GFP (Addgene plasmid 20672) has been deposited by Tannishtha Reya. We thank Martin Zenke UK Aachen for critical comments and suggestions.

\section{Author contributions}

$\mathrm{NH}, \mathrm{TR}, \mathrm{IG}, \mathrm{VJ}$ and $\mathrm{HS}$ conceived and designed the experiments. NH, TR, KB and ZL performed the experiments. NH, TR, IG, HF and $\mathrm{HS}$ analyzed the data. IG evaluated histologic sections. HS and VJ contributed reagents/materials/analysis tools. $\mathrm{NH}$ and HS wrote the manuscript.

1. Ogawa M, Nishikawa S, Yoshinaga K, Hayashi S, Kunisada T, Nakao J et al. Expression and function of $\mathrm{c}$-Kit in fetal hemopoietic progenitor cells: transition from the early c-Kitindependent to the late $\mathrm{c}$-Kit-dependent wave of hemopoiesis in the murine embryo. Development 1993; 117: 1089-1098.

2. De Jong MO, Westerman $Y$, Wagemaker G, Wognum AW. Coexpression of Kit and the receptors for erythropoietin, interleukin 6 and GM-CSF on hemopoietic cells. Stem Cells 1997; 15: 275-285.
3. Wu H, Liu X, Jaenisch R, Lodish HF. Generation of committed erythroid BFU-E and CFU-E progenitors does not require erythropoietin or the erythropoietin receptor. Cell 1995; 83: 59-67.

4. De Aberle SB. A study of the hereditary anaemia of mice. Am J Anat 1927; 40: 219-249.

5. Pircher TJ, Geiger JN, Zhang D, Miller CP, Gaines P, Wojchowski DM. Integrative signaling by minimal erythropoietin receptor forms and c-Kit. J Biol Chem 2001; 276: 8995-9002.

6. Tan BL, Hong L, Munugalavadla V, Kapur R. Functional and biochemical consequences of abrogating the activation of multiple diverse early signaling pathways in Kit. Role for Src kinase pathway in Kit-induced cooperation with erythropoietin receptor. J Biol Chem 2003; 278: 11686-11695

7. Sui $X$, Krantz SB, You M, Zhao Z. Synergistic activation of MAP kinase (ERK1/2) by erythropoietin and stem cell factor is essential for expanded erythropoiesis. Blood 1998; 92: $1142-1149$.

8. Muta K, Krantz SB, Bondurant MC, Dai CH. Stem cell factor retards differentiation of normal human erythroid progenitor cells while stimulating proliferation. Blood 1995; 86: 572-580.

9. Geslain R, Uddin S, Liu H, Jiang H, van Besien K, Pan T et al. Distinct functions of erythropoietin and stem cell factor are linked to activation of mTOR kinase signaling pathway in human erythroid progenitors. Cytokine 2013; 61: 329-335.

10. Muta K, Krantz SB, Bondurant MC, Wickrema A. Distinct roles of erythropoietin, insulin-like growth factor I, and stem cell factor in the development of erythroid progenitor cells. J Clin Invest 1994; 94: 34-43.

11. Miura $Y$, Miura $O$, Ihle JN, Aoki N. Activation of the mitogen-activated protein kinase pathway by the erythropoietin receptor. J Biol Chem 1994; 269: 29962-29969.

12. Klingmüller U, Wu H, Hsiao JG, Toker A, Duckworth BC, Cantley LC et al. Identification of a novel pathway important for proliferation and differentiation of primary erythroid progenitors. Proc Natl Acad Sci USA 1997; 94: 3016-3021.

13. Arcasoy MO, Jiang $X$. Co-operative signalling mechanisms required for erythroid precursor expansion in response to erythropoietin and stem cell factor. $\mathrm{Br} J$ Haematol 2005; 130: 121-129.

14. Linnekin D, Deberry CS, Chem JB, Mou S. Lyn associates with the juxtamembrane region of c-Kit and is activated by stem cell factor in hematopoietic cell lines and normal progenitor cells. J Biol Chem 1997; 272: 27450-27455.

15. Lennartsson J, Blume-Jensen P, Hermanson M, Pontén E, Carlberg M, Rönnstrand L. Phosphorylation of Shc by Src family kinases is necessary for stem cell factor receptor/c-kit mediated activation of the Ras/MAP kinase pathway and c-fos induction. Oncogene 1999; 18: 5546-5553.

16. Slavova-Azmanova NS, Kucera N, Louw A, Satiaputra J, Handoko A, Singer P et al. Lyn kinase plays important roles in erythroid expansion, maturation and Epo-receptor signaling by regulating inhibitory signaling pathways that control survival. Biochem J 2014; 459: 455-466.

17. Remy I, Wilson IA, Michnick SW. Erythropoietin receptor activation by a ligand-induced conformation change. Science 1999; 283: 990-993.

18. Tsai FY, Orkin SH. Transcription factor GATA-2 is required for proliferation/survival of early hematopoietic cells and mast cell formation, but not for erythroid and myeloid terminal differentiation. Blood 1997; 89: 3636-3643.

19. Mucenski ML, McLain K, Kier AB, Swerdlow SH, Schreiner CM, Miller TA et al. A functional c-myb gene is required for normal murine fetal hepatic hematopoiesis. Cell 1991; 65: 677-689.

20. Dubois NC, Adolphe C, Ehninger A, Wang R a, Robertson EJ, Trumpp A. Placental rescue reveals a sole requirement for $\mathrm{c}-\mathrm{Myc}$ in embryonic erythroblast survival and hematopoietic stem cell function. Development 2008; 135: 2455-2465.

21. Gregory T, Yu C, Ma a, Orkin SH, Blobel G a, Weiss MJ. GATA-1 and erythropoietin cooperate to promote erythroid cell survival by regulating bcl-xL expression. Blood 1999; 94: $87-96$.

22. Weiss MJ, Keller G, Orkin SH. Novel insights into erythroid development revealed through in vitro differentiation of GATA-1 embryonic stem cells. Genes Dev 1994; 8: 1184-1197.

23. Fujiwara Y, Browne CP, Cunniff K, Goff SC, Orkin SH. Arrested development of embryonic red cell precursors in mouse embryos lacking transcription factor GATA-1. Proc Natl Acad Sci USA 1996; 93: 12355-12358.

24. Hall MA, Curtis DJ, Metcalf D, Elefanty AG, Sourris $K$, Robb $L$ et al. The critical regulator of embryonic hematopoiesis, SCL, is vital in the adult for megakaryopoiesis, erythropoiesis, and lineage choice in CFU-S12. Proc Natl Acad Sci USA 2003; 100: 992-997.

25. Xiang Z, Kreisel F, Cain J, Colson A, Tomasson MH. Neoplasia driven by mutant C-KIT is mediated by intracellular, not plasma membrane, receptor signaling. Mol Cell Biol 2007; 27: 267-282.

26. Bodemer C, Hermine O, Palmérini F, Yang Y, Grandpeix-Guyodo C, Leventhal PS et al. Pediatric mastocytosis is a clonal disease associated with D816V and other activating c-KIT mutations. J Invest Dermatol 2010; 130: 804-815

27. Malaise M, Steinbach D, Corbacioglu S. Clinical implications of $c$-Kit mutations in acute myelogenous leukemia. Curr Hematol Malig Rep 2009; 4: 77-82.

28. De Felipe P, Ryan MD. Targeting of proteins derived from self-processing polyproteins containing multiple signal sequences. Traffic 2004; 5: 616-626.

29. Hayashi S, Lewis P, Pevny L, McMahon AP. Efficient gene modulation in mouse epiblast using a Sox2Cre transgenic mouse strain. Mech Dev 2002; 119(Suppl): S97-S101.

30. De Boer J, Williams A, Skavdis G, Harker N, Coles M, Tolaini M et al. Transgenic mice with hematopoietic and lymphoid specific expression of Cre. Eur J Immunol 2003; 33: 314-325. 
31. Goossens S, Janzen V, Bartunkova S, Yokomizo T, Drogat B, Crisan M et al. The EMT regulator Zeb2/Sip1 is essential for murine embryonic hematopoietic stem/progenitor cell differentiation and mobilization. Blood 2011; 117: 5620-5630.

32. Zhang J, Socolovsky M, Gross AW, Lodish HF. Role of Ras signaling in erythroid differentiation of mouse fetal liver cells: functional analysis by a flow cytometry-based novel culture system. Blood 2003; 102: 3938-3946.

33. Pop R, Shearstone JR, Shen Q, Liu Y, Hallstrom K, Koulnis M et al. A key commitment step in erythropoiesis is synchronized with the cell cycle clock through mutual inhibition between PU.1 and S-phase progression. PLOS Biol 2010; 8: 1-19.

34. Sprüssel A, Schulte JH, Weber S, Necke M, Händschke K, Thor T et al. Lysine-specific demethylase 1 restricts hematopoietic progenitor proliferation and is essential for terminal differentiation. Leukemia 2012; 26: 2039-2051.

35. Von Lindern M, Deiner EM, Dolznig H, Parren-Van Amelsvoort M, Hayman MJ, Mullner EW et al. Leukemic transformation of normal murine erythroid progenitors: v- and c-ErbB act through signaling pathways activated by the EpoR and c-Kit in stress erythropoiesis. Oncogene 2001; 20: 3651-3664.

36. Carotta S, Pilat S, Mairhofer A, Schmidt U, Dolznig H, Steinlein P et al. Directed differentiation and mass cultivation of pure erythroid progenitors from mouse embryonic stem cells. Blood 2004; 104: 1873-1880.

37. Sathyanarayana P, Dev A, Fang J, Houde E, Bogacheva O, Bogachev $O$ et al. EPO receptor circuits for primary erythroblast survival. Blood 2008; 111: 5390-5399.

38. Asano H, Fukunaga S, Deguchi Y, Kawamura S, Inaba M. Bcl-xL and Mcl-1 are involved in prevention of in vitro apoptosis in rat late-stage erythroblasts derived from bone marrow. J Toxicol Sci 2012; 37: 23-31.

39. Sandoval H, Thiagarajan P, Dasgupta SK, Schumacher A, Prchal JT, Chen M et al. Essential role for Nix in autophagic maturation of erythroid cells. Nature 2008; 454: 232-235.

40. Aerbajinai W, Giattina M, Lee YT, Raffeld M, Miller JL. The proapoptotic factor Nix is coexpressed with Bcl-xL during terminal erythroid differentiation. Blood 2003; 102: 712-717.

41. Matsumoto A, Masuhara M, Mitsui K, Yokouchi M, Ohtsubo M, Misawa $\mathrm{H}$ et al. CIS, a cytokine inducible SH2 protein, is a target of the JAK-STAT5 pathway and modulates STAT5 activation. Blood 1997; 89: 3148-3154.

42. Jegalian $A G, W u H$. Regulation of Socs gene expression by the proto-oncoprotein GFI-1B: two routes for STAT5 target gene induction by erythropoietin. J Biol Chem 2002; 277 2345-2352.

43. Kapur R, Zhang L. A novel mechanism of cooperation between c-Kit and erythropoietin receptor. Stem cell factor induces the expression of Stat5 and erythropoietin receptor, resulting in efficient proliferation and survival by erythropoietin. $J$ Biol Chem 2001; 276: 1099-1106.

44. Van Dijk TB, van Den Akker E, Amelsvoort MP, Mano H, Löwenberg B, von Lindern M. Stem cell factor induces phosphatidylinositol 3'-kinase-dependent Lyn/Tec/Dok-1 complex formation in hematopoietic cells. Blood 2000; 96: 3406-3413.

45. Schittenhelm MM, Shiraga S, Schroeder A, Corbin AS, Griffith D, Lee FY et al. Dasatinib (BMS-354825), a dual SRC/ABL kinase inhibitor, inhibits the kinase activity of wild-type, juxtamembrane, and activation loop mutant KIT isoforms associated with human malignancies. Cancer Res 2006; 66: 473-481.
46. Blake RA, Broome MA, Liu X, Wu J, Gishizky M, Sun L et al. SU6656, a selective src family kinase inhibitor, used to probe growth factor signaling. Mol Cell Biol 2000; 20: 9018-9027.

47. Jayapal SR, Lee KL, Ji P, Kaldis P, Lim B, Lodish HF. Down-regulation of Myc is essential for terminal erythroid maturation. J Biol Chem 2010; 285: 40252-40265.

48. Clarke MF, Kukowska-Latallo JF, Westin E, Smith M, Prochownik EV. Constitutive expression of a c-myb cDNA blocks Friend murine erythroleukemia cell differentiation. Mol Cell Biol 1988; 8: 884-892.

49. Briegel K, Lim KC, Plank C, Beug H, Engel JD, Zenke M. Ectopic expression of a conditional GATA-2/estrogen receptor chimera arrests erythroid differentiation in a hormonedependent manner. Genes Dev 1993; 7: 1097-1109.

50. Bartůnek P, Králová J, Blendinger G, Dvorák M, Zenke M. GATA-1 and c-myb crosstalk during red blood cell differentiation through GATA-1 binding sites in the c-myb promoter. Oncogene 2003; 22: 1927-1935.

51. Rylski M, Welch JJ, Chen Y-Y, Letting DL, Diehl JA, Chodosh LA et al. GATA-1-mediated proliferation arrest during erythroid maturation. Mol Cell Biol 2003; 23: 5031-5042.

52. Grass JA, Boyer ME, Pal S, Wu J, Weiss MJ, Bresnick EH. GATA-1-dependen transcriptional repression of GATA-2 via disruption of positive autoregulation and domainwide chromatin remodeling. Proc Natl Acad Sci USA 2003; 100: 8811-8816.

53. Zeuner a, Francescangeli F, Signore M, Venneri M a, Pedini F, Felli N et al. The Notch2Jagged1 interaction mediates stem cell factor signaling in erythropoiesis. Cell Death Differ 2011; 18: 371-380.

54. Zeuner A, Pedini F, Signore M, Testa U, Pelosi E, Peschle C et al. Stem cell factor protects erythroid precursor cells from chemotherapeutic agents via up-regulation of BCL-2 family proteins. Blood 2003; 102: 87-93.

55. Bouscary D, Pene F, Claessens Y-E, Muller O, Chrétien S, Fontenay-Roupie M et al. Critical role for PI 3-kinase in the control of erythropoietin-induced erythroid progenitor proliferation. Blood 2003; 101: 3436-3443.

56. Hong L, Ramdas B, Chen J, Harris C, Wojchowski DM, Kapur R. KIT associated intracellular tyrosines play an essential role in EpoR co-signaling. Cell Signal 2008; 20: 1513-1520.

57. Gerbaulet A, Wickenhauser C, Scholten J, Peschke K, Drube S, Horny H-P et al. Mast cell hyperplasia, B-cell malignancy, and intestinal inflammation in mice with conditional expression of a constitutively active kit. Blood 2011; 117: 2012-2021.

58. Deshpande S, Bosbach B, Yozgat Y, Park CY, Moore MAS, Besmer P. Kit receptor gain-offunction in hematopoiesis enhances stem cell self-renewal and promotes progenitor cell expansion. Stem Cells 2013; 31: 1683-1695.

59. Oh P, Lobry C, Gao J, Tikhonova A, Loizou E, Manent J et al. In vivo mapping of notch pathway activity in normal and stress hematopoiesis. Cell Stem Cell 2013; 13: 190-204.

60. Moenning A, Jäger R, Egert A, Kress W, Wardelmann E, Schorle H. Sustained plateletderived growth factor receptor alpha signaling in osteoblasts results in craniosynostosis by overactivating the phospholipase C-gamma pathway. Mol Cell Biol 2009; 29: 881-891.

61. Soriano P. Generalized lacZ expression with the ROSA26 Cre reporter strain. Nat Genet 1999; 21: 70-71.

62. Robanus-Maandag E, Dekker M, van der Valk M, Carrozza M-L, Jeanny J-C, Dannenberg J-H et al. p107 is a suppressor of retinoblastoma development in pRb-deficient mice. Genes Dev 1998; 12: 1599-1609.

\section{Supplementary Information accompanies this paper on Cell Death and Differentiation website (http://www.nature.com/cdd)}

